\title{
A comparison of antrafenine and aspirin on platelet aggregation and frusemide-induced diuresis
}

\author{
S. M. HASSAN \\ M.B. B.S. \\ Alice Olivesi \\ M.D. \\ AlisON Fish \\ PAUl TURner \\ M.D., B.Sc., F.R.C.P.

\begin{abstract}
Department of Clinical Pharmacology, St Bartholomew's Hospital, and Charterhouse Clinical Research Unit Limited, London ECI
\end{abstract}

\begin{abstract}
Summary
The effects of antrafenine were compared with aspirin and placebo on platelet aggregation and on the diuretic action of frusemide in normal volunteers. Aspirin significantly reduced platelet aggregation at 3 and $6 \mathrm{hr}$ after administration, but antrafenine only at $3 \mathrm{hr}$. Only aspirin significantly reduced the increase in urine sodium and potassium produced by frusemide.
\end{abstract}

Antrafenine, an anthranilic acid ester derivative, is an analgesic agent which inhibits prostaglandin synthesis and has some anti-inflammatory properties (Wisanto et al., 1981). Other anti-inflammatory analgesics such as aspirin have been shown to inhibit, at least in part, the diuretic action of frusemide (Henry, 1980) and to inhibit platelet aggregation (Zucker and Peterson, 1968). The authors have compared the effects of antrafenine and aspirin on platelet aggregation and frusemide-induced diuresis in normal human volunteers.

\section{Material and methods}

Six healthy volunteers ( 5 male, 1 female) aged 20-22 years participated in the study. A history of peptic ulcer, analgesic-induced asthma and other chronic illness was excluded in all subjects, who abstained from use of any medication for at least one week before the study and from smoking on the days of the study. After a light breakfast of toast and fruit-juice they were given with $100 \mathrm{ml}$ water the following treatments at weekly intervals in a double-blind randomized order based on 2 Latin squares, using a double-dummy technique:(a) aspirin $600 \mathrm{mg}$ in a capsule; (b) antrafenine $300 \mathrm{mg}$ as two $150 \mathrm{mg}$ tablets; (c) matching capsule and tablet placebos.

One hour after this treatment frusemide $20 \mathrm{mg}$ as a tablet was given.
The bladder was emptied before frusemide ingestion and a urine aliquot collected. All urine passed was then collected at hourly intervals for 7 $\mathrm{hr}$, and urine volume, $\mathrm{Na}^{+}$and $\mathrm{K}^{+}$estimated.

Nine-millilitre blood samples were collected immediately before each analgesic treatment or placebo, and at 3 and $6 \mathrm{hr}$ later into $1-\mathrm{ml} \mathrm{3.8 \%}$ trisodium citrate solution.

Platelet-rich plasma was prepared as the supernatant after centrifugation at $120 \mathrm{~g}$ for $5 \mathrm{~min}$. The remainder was centrifuged at $600 \mathrm{~g}$ for $5 \mathrm{~min}$ to prepare platelet-poor plasma. Platelet aggregation was measured in a Payton-Dual aggregometer using 1,2 and $4 \mathrm{~mol} \mu \mathrm{mol}$ adenosine diphosphate (ADP)

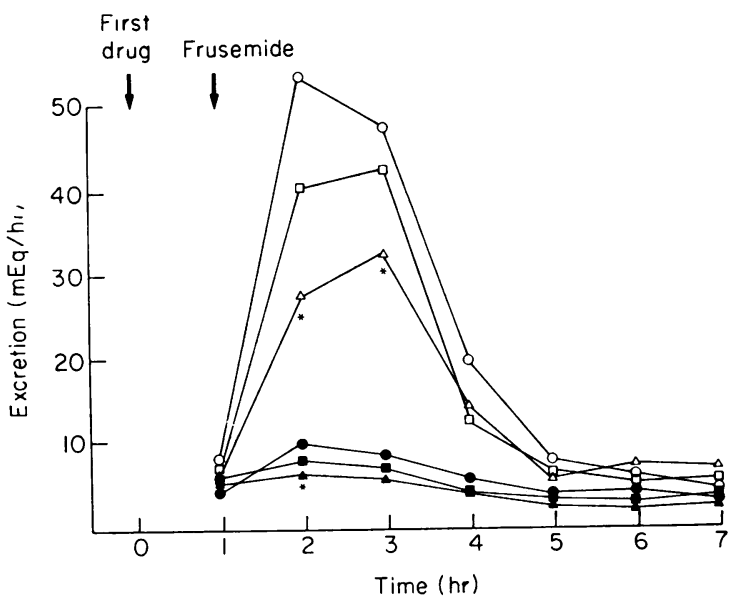

FIG. 1. Urinary excretion of sodium (unfilled symbols) and potassium (filled symbols) following administration of aspirin $(-\triangle-)$, antrafenine ( $\square-$ ) and placebo ( $-\mathrm{O}-$ ) followed by frusemide. ${ }^{*}$ indicates a significant difference of aspirin from placebo $(P=0 \cdot 05)$. 
TABLE 1. Shifts of adenosine diphosphate-induced platelet aggregation expressed as dose-ratios compared with pre-treatment values in 6 subjects

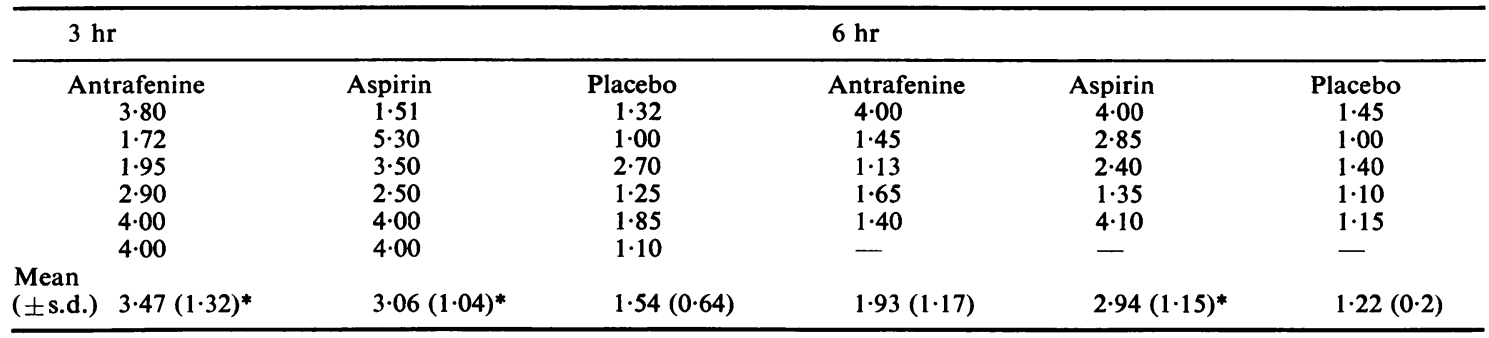

${ }^{*} p<0.05$ - paired $t$-test in comparison with placebo.

as the aggregating agent. Lateral shifts of the dose ratios were calculated for each blood sample.

\section{Results \\ Urinary estimations}

Aspirin significantly $(P=0.05)$ reduced the frusemide-induced increase in sodium excretion at 2 and $3 \mathrm{hr}$, and potassium excretion at $2 \mathrm{hr}$ (Fig. 1), but had no significant effect on urine volume. Antrafenine had no significant influence on either electrolyte excretion or urine volume.

\section{Platelet aggregation}

Both aspirin and antrafenine inhibited ADPinduced platelet aggregation at $3 \mathrm{hr}(P<0.05)$, but only aspirin had a significant inhibitory effect at $6 \mathrm{hr}(P<0.05)($ Table 1$)$.

\section{Discussion}

The mechanism underlying the inhibitory influence of non-steroidal anti-inflammatory drugs on the diuretic and anti-hypertensive effects of frusemide and thiazide diuretics is still uncertain. Although a pharmacokinetic mechanism may be present (Benet, 1979), it is also possible that the interaction involves inhibition of prostaglandin synthesis in the kidneys (Patak et al., 1975; Abe et al., 1978). Platelet aggregation is also thought to involve prostaglandin activity, and the anti-aggregatory effect of aspirin to involve inhibition of prostaglandin synthesis. This effect is permanent because aspirin irreversibly acetylates the platelet cyclooxygenase enzyme involved in prostaglandin synthesis (Roth et al., 1977). Platelet aggregation does not then return to normal until a new generation of platelets have entered the circulation (Marian, Packham and Mustard, 1980).

Antrafenine appears to differ from aspirin in certain important aspects. Firstly, although it has a marked inhibitory effect on platelet aggregation at $3 \mathrm{hr}$ after administration, comparable to the effect of aspirin, this effect has disappeared at $6 \mathrm{hr}$ while the effect of aspirin, as expected, is unchanged. Its effects in the platelet, therefore, appear to be reversible in comparison with the irreversible effects of aspirin. Secondly, while aspirin has a significant inhibitory effect on the sodium and potassium excretion induced by frusemide, antrafenine had no measurable effect under the conditions of this study, although such an effect in larger doses cannot be excluded. It can be concluded, however, that doses of aspirin and antrafenine with similar effects on platelet aggregation at $3 \mathrm{hr}$ after ingestion had markedly different effects on frusemide-induces sodium and potassium excretion. The dose of antrafenine used, $300 \mathrm{mg}$, had been shown to be a effective analgesic in preliminary clinical testing (A. Hedges and P. Turner, personal communication) and in controlled double-blind clinical trials (Wisanto et al., 1981).

The clinical importance of these pharmacological differences has yet to be explored. Bown et al. (1980) found that faecal blood loss after 7 days' treatment with antrafenine 450 and $900 \mathrm{mg}$ daily was similar to that after placebo and significantly less than that after aspirin $1800 \mathrm{mg}$ daily, but experience of its use is still too limited to conclude that it produces fewer episodes of major blood loss. There is little doubt that anti-inflammatory drugs such as aspirin and indomethacin can antagonize the effects of diuretics and precipitate heart failure (Turner and Warrington, 1980).

It will be interesting to see if the absence of interaction of antrafenine with frusemide in this single-dose volunteer study truly predicts a lack of this action in the clinical situation.

\section{Acknowledgments}

Salim Hassan is supported by a Scholarship from the Government of Iraq, Alice Olivesi by a fellowship from Hoechst Limited, and Alison Fish by the British Heart Foundation. We thank Synthelabo Limited for supplying antrafenine and financial support, and $\mathrm{Mr} \mathrm{N}$. Hathway for statistical help. 


\section{References}

Abe, K., Irokawa, N., Yasujima, M., Seino, M., Chiba, S., Sakurai, Y., Yoshinaga, K. \& SaIto, T. (1978) The kallikrein-kinin system and prostaglandins in the kidney, their relations to frusemide-induced diuresis and to the renin-angiotensin-aldosterone system in man. Circulation Research, 43, 254.

BENET, L.Z. (1979) Pharmacokinetics/pharmacodynamics of frusemide in man: a review. Journal of Pharmacokinetics and Biopharmacy, 7, 1.

Bown, R.L., Martin, B.K., Gordon, A., Seymour, D., Rovei, V., Gomeni, C., Narbonne, G. \& Coquelin, J.P. (1980) Comparative study of gastro-intestinal blood loss after antrafenine, aspirin and placebo in healthy volunteers. Thérapie, 35, 685 .

HenRY, J.A. (1980) Salicylate-frusemide interaction. British Journal of Pharmacology, 70, 159P.

Marian, A., Packham, M.A. \& Mustard, J.F. (1980) Pharmacology of platelet-affecting drugs. Circulation, 62 (Suppl.), V 26.

Patak, R., Mookerjee, B., Bentzel, C., Hysert, P.,
Babea, M. \& Leo, J. (1975) Antagonism of the effect of frusemide by indomethacin in normal and hypertensive man. Prostaglandins, 10, 649.

Roth, G.J., Stanford, N., Jacobs, J.W. \& Majerus, P.W. (1977) Acetylation of prostaglandin synthetase by aspirin. Purification and properties of the acetylated protein from sheep vesicular gland. Biochemistry, 16, 4244.

Turner, P. \& Warrington, S.J. (1980) Drug interactions involving adrenergic neurone blocking drugs. In: Cardiovascular and Respiratory Disease Therapy (Ed by Petrie, J.C.). Elsevier/North Holland, Amsterdam.

Wisanto, A., Caudron, J., Dubois, D., Narbonne, G. \& Coquelin, J.P. (1981) A double-blind placebo-controlled single dose study comparing antrafenine and placebo in patients with post-episiotomy pain. Current Therapeutic Research, 29, 171.

Zucker, M.B. \& Peterson, J. (1968) Inhibition of ADP in induced secondary aggregation and other platelet functions by acetyl salicyclic acid ingestion. Proceedings of the Society for Experimental Biology and Medicine, 127, 547. 